\title{
Timber industry waste-teak (Tectona grandis Linn.) leaf extract mediated synthesis of antibacterial silver nanoparticles
}

\author{
Aishwarya Devadiga $^{1} \cdot$ K. Vidya Shetty ${ }^{1} \cdot$ M. B. Saidutta ${ }^{1}$
}

Received: 20 January 2015/ Accepted: 20 July 2015/Published online: 7 August 2015

(c) The Author(s) 2015. This article is published with open access at Springerlink.com

\begin{abstract}
The current research article emphasizes efficacious use of teak leaves, an agro -biowaste from world's premier hardwood timber industry, for "green" synthesis of silver nanoparticles (AgNPs). Bioactive compounds of the leaves act as prolific reducing and stabilizing agents in AgNP synthesis. The characterization of the AgNPs synthesized using teak leaves revealed that the particles are spherical with an average size of $28 \mathrm{~nm}$ and the presence of bioactive compounds present in teak leaf extract as capping agents on the nanoparticles. A prominent decrease in the content of bioactive compounds such as polyphenols, antioxidants and flavonoids after the biosynthesis of AgNPs signifies that these class of compounds act as reductants and stabilizers during biosynthesis. The biosynthesized silver nanoparticles were also successfully evaluated for their antibacterial characteristics against waterborne pathogens, E. coli and S. aureus, with minimum inhibitory concentration of $25.6 \mu \mathrm{g} / \mathrm{mL}$. Exploitation of agrowaste resources for synthesis of AgNPs curtails indiscriminate usage of food and commercial plant materials, rather contributing a sustainable way for effective plant waste biomass utilization and management. The biosynthesized AgNps have potential application in water purifiers, antibacterial fabrics, sports wear and in cosmetics
\end{abstract}

K. Vidya Shetty

vidyaks68@yahoo.com; vidyaks95@nitk.ac.in

Aishwarya Devadiga

aishwarya.d.88@gmail.com

M. B. Saidutta

mbs@nitk.ac.in

1 Department of Chemical Engineering, National Institute of Technology Karnataka, Surathkal, Srinivasnagar Post, Mangalore 575025, Karnataka, India as antibacterial agent and the process used for its synthesis being greener is highly beneficial from environmental, energy consumption and economic perspectives.

Keywords Teak - Silver nanoparticles - Biosynthesis . Timber industry waste $\cdot$ Antibacterial property

\section{Introduction}

Silver nanoparticles (AgNps) have attained significant importance as high-demand commercial nanoproducts [15] and have found profound applications in aspects of human lifestyle ranging from cosmetics, paints, textiles and sportswear and in home appliances. The major routes for biosynthesis of metallic nanoparticles comprise of physical [6-8], chemical [9-11] and biological methods [12-14]. AgNps synthesized using physical and chemical routes contain chemical surfactants that render the AgNps less biocompatible. Moreover, physical and chemical synthesis routes involve high temperature for synthesis which renders it uneconomical due to large energy consumption. These methods also involve the use of toxic and hazardous solvents and chemicals that pose harm to the ecosystem upon their release, raising concerns about the environmental footprint of the process and also included high capital investment. Biological routes for AgNps synthesis have been gaining the attention of researchers as it overcomes the shortcomings of physical and chemical processes. Biological routes comprise resources such as bacteria, fungi, algae and plants for the synthesis of AgNps. Biological routes are preferred, as they do not involve the usage of toxic and hazardous reducing agents and surfactants and make use of less elevated process parameters. Microbial counterparts in comparison to plants require 
continuous supply of nutrients and maintenance of sterile conditions and offer slow rates of synthesis, thus making plants a suitable choice for the synthesis of AgNps [15-19]. Plant resources such as Cinnamon zeylanicum [20] Emblica officinalis fruit [21] and Catharanthus roseus [22] have been used in the synthesis of AgNps. These plant resources possess food and agro-economic value. Hence, it becomes necessary to exploit nonfood value and agronomic byproducts or wastes to increase the overall efficiency of "Green synthesis of nanoparticles". With a view to promote the concept of harnessing the efficacy of nonfood value and agronomic by-products, the leaves of Tectona grandis. Linn $\mathrm{f}$. were chosen as a plant bioresource for the green synthesis of $\mathrm{AgNps}$.

Tectona grandis. Linn (Teak) is a large deciduous tree and an indigenous native of Asia, reputed as Sagwan (Hindi), Saka (Sanskrit) and teak tree (English). Its growing demand as the world's premium hardwood has initiated several countries lying in the tropical belt to grow them in huge plantations. Consequently, the proportion of foliage that forms the refuse of the timber industry is enormous, making it an ideal resource for the green synthesis of AgNps. Teak leaves constitute a huge array of bioactive compounds: Quinones such as tectoquinone, lapachol, deoxylapachol and its isomer, tectoleafoquinone, anthraquinone -napthaquinone pigment, steroidal compounds such as squalene, poly isoprene- a- tolyl methyl ether betulinic acid, tectograndone, monoterpene, apocarotenoids such as tectoinols-A, tectoionols-B, glycosides such as anthraquinone glycosides, phenolic acids such as tannic acid, gallic acid, ferulic acid, caffeic acid and ellagic acid, flavonoids such as rutin and quercitin, saponins, proteins, calcium, phosphorous and dye [23]. Extracts obtained from teak leaves have demonstrated antioxidant activities, free radical scavenging properties [24], diuretic and antibacterial property [25]. These "bioreservoirs" of active components go untapped as the timber obtained from these trees is used for lumbering while the leaves end up as agrowaste. The potency of these leaves can be consigned towards biosynthesis of AgNps. The precept of utilizing agrowaste resources for the synthesis of AgNps affirms to be green, self-sustaining and environmentally benign [26]. Elaborate and extensive work has been carried out by Cruz et al. [27] and Sathishkumar et al. [20] proving the efficiency of plant-mediated biosynthesis of nanoparticles as a faster process. Nanoparticles synthesized using plant material are known to be capped by bioactive components present in the plant material [28].

In the present work, Teak leaves, an unharnessed agricultural waste, have been exploited as a resource for the effectual green synthesis of AgNps under ambient conditions using the aqueous extract obtained from the leaves containing a multitude of bioactive compounds that act as reducing and capping agents for AgNps. This synthesis route is innovative (1) in channeling agrowaste towards the synthesis of AgNps that are antibacterial, (2) in use of non-harsh ambient synthesis conditions, thus making it energy efficient and cost effective and (3) involvement of no organic solvents, thus making it environmental friendly and economical. These features serve to make the process as a green route for the synthesis of nanoparticles.

\section{Materials and methods}

\section{Collection of the plant material}

Teak leaves were collected from Surathkal, a coastal town situated in the state of Karnataka, India, geographically positioned at coordinates $12^{\circ} 58^{\prime} 60 \mathrm{~N} \quad 74^{\circ} 46^{\prime} 60 \mathrm{E}$. The freshly harvested leaves were rinsed thrice with tap water and twice with distilled water to eliminate impurities such as dust and soil. The prewashed teak leaves were shade dried in dust-free conditions for 10 days. The shade-dried leaves were further finely ground into a powder using a motor-operated domestic blade mixer (Ultra, India) and stored in amber colored dry containers for further usage.

\section{Preparation of the aqueous teak leaf extract}

The aqueous extract of leak leaves was prepared by adding $10 \mathrm{~g}$ of the processed teak leaf powder to $100 \mathrm{~mL}$ of deionized water in a beaker and the leaf suspension was heated under slow heating until the suspension boiled. The suspension was further allowed to boil for $2 \mathrm{~min}$ with continuous stirring. The suspension was then cooled to a temperature of $28 \pm 2{ }^{\circ} \mathrm{C}$ and filtered through Whattmann No. 1 filter paper to eliminate any plant material; thus obtained teak leaf extract was stored in amber colored air tight bottles at $4{ }^{\circ} \mathrm{C}$ for further usage.

\section{Biosynthesis of silver nanoparticles}

$100 \mathrm{~mL}$ of $1 \mathrm{mM}$ solution of silver nitrate was prepared and used as the precursor salt solution and $25 \mathrm{~mL}$ of teak leaf extract prepared according to the protocol mentioned in Sect. 2.2, was added to the reaction vessel containing the precursor salt solution. The reaction mixture was continuously agitated using a magnetic stirrer at the temperature of $28 \pm 2{ }^{\circ} \mathrm{C}$ and the solution was observed for the formation of brown color which is the characteristic color change indicating the formation of $\mathrm{AgNps}$. 
UV-visible spectral analysis of the biosynthesized silver nanoparticles

Aliquots of the sample were withdrawn from the reaction mixture at various time intervals and suitably diluted for the analysis. The experiments for biosynthesis of AgNps were carried out in triplicates. The samples of reaction mixture were subjected to spectral analysis at resolution of $1 \mathrm{~nm}$ from 300 to $700 \mathrm{~nm}$ using dual beam UV-vis spectrophotometer (Labomed, USA) to determine the surface plasmon peak characteristic of AgNps. The mean values of the spectral data were plotted.

\section{XRD analysis of the biosynthesized silver nanoparticles}

The suspension of the biosynthesized AgNps after $24 \mathrm{~h}$ of synthesis time was centrifuged at $15,000 \mathrm{rpm}$ for $10 \mathrm{~min}$ to separate the AgNps. The AgNps obtained after centrifugation were washed with deionized water and dried overnight at $130{ }^{\circ} \mathrm{C}$ in a hot air oven. These dried nanoparticles were then used for characterization. The powdered AgNps were then drop coated and subjected to XRD analysis (JEOL), with $\mathrm{Cu} \mathrm{k \alpha} 1.5418 \AA$, voltage of $30 \mathrm{kV}$ and current at $20 \mathrm{~mA}$ and at a scan speed of $2 \mathrm{~nm}$ over the range of $2 \theta$ values from $20^{\circ}$ to $80^{\circ}$.

\section{Transmission electron microscopy analysis of the biosynthesized nanoparticles}

The dried AgNps were analyzed by transmission electron microscopy (JEM 2100, Japan) and were also subjected to energy dispersive $\mathrm{X}$ - ray analysis (EDX).

\section{FTIR analysis}

FTIR analysis of the dried AgNP powder was recorded using Avatar 360 IR spectrophotometer in the range of $4000-400 \mathrm{~cm}^{-1}$ to determine the functional groups present on the surface of the nanoparticles.

\section{Determination of yield of silver nanoparticles by atomic absorption spectroscopy (AAS)}

Silver ions in $\mathrm{AgNO}_{3}$ are reduced to $\mathrm{AgNps}$ through the action of bioactive compounds present in teak leaf extract. By measuring the initial and final concentration of silver ions in synthesis mixture, the amount of $\mathrm{Ag}$ ions reduced to silver nanoparticles can be calculated [29, 30]. Hence, the yield of $\mathrm{Ag}$ nanoparticles can be determined. Residual silver ions present in the supernatant obtained after biosynthesis were determined using AAS (GBC-932 PLUS). The amount of residual silver ions was expressed as final concentration in $\mathrm{mg} / \mathrm{L}$ and the percentage yield of AgNps based on initial Ag ions concentration in synthesis mixture was calculated using Eq. (1).

Percentage yield $=\left(\frac{c_{\mathrm{i}}-c_{\mathrm{r}}}{c_{\mathrm{i}}}\right) \times 100$,

where $C_{\mathrm{i}}$ is the initial concentration of $\mathrm{Ag}$ ions $(\mathrm{mg} / \mathrm{L})$ and $C_{\mathrm{r}}$ is the final residual concentration of $\mathrm{Ag}$ ions $(\mathrm{mg} / \mathrm{L})$.

\section{Evaluation of the role of bioactive compounds in mediating biosynthesis of silver nanoparticles}

Teak leaves are known to contain several bioactive phytocomponents like tannins, phenolic acids and flavonoids which play a crucial role as scavengers of free radicals. These compounds are known to mediate biosynthesis of AgNps. Hence, to evaluate their role, assays for total phenolic concentration, total flavonoid concentration and total antioxidant content were performed on the aqueous leaf extract as well as the supernatant obtained after biosynthesis of AgNps. These assays can elucidate the subsequent role of the bioactive phytocomponents present in the aqueous teak leaf extract as capping and reducing agents.

\section{Total phenolic content (TPC)}

Total phenolic content was analyzed by Folin-Ciocalteu's method. $0.3 \mathrm{~mL}$ of the sample was mixed with $1.5 \mathrm{~mL}$ Folin-Ciocalteu's phenol reagent $(10 \% \mathrm{v} / \mathrm{v})$ and $1.2 \mathrm{~mL}$ $7.5 \%$ w/v $\mathrm{Na}_{2} \mathrm{CO}_{3}$. The above solution was thoroughly mixed and incubated in dark for $30 \mathrm{~min}$. The absorbance was measured at $765 \mathrm{~nm}$ [31, 32] using UV-vis spectrophotometer (Labomed, USA). Total phenolic content was determined in terms of $\mu \mathrm{g}$ of Gallic acid equivalents (GAE)/mL using the precalibrated data with the Gallic acid standards.

\section{Total flavonoid content (TFC)}

The flavonoid contents in the samples were determined spectrophotometrically using the method of Ordon-Ez et al. [33] based on the formation of a complex flavonoid-aluminum and spectral determination at $420 \mathrm{~nm}$ using UV-vis spectrophotometer (Labomed, USA). $0.5 \mathrm{~mL}$ of the sample was made to react with an equal volume of $2 \% \mathrm{AlCl}_{3}$ ethanol solution at room temperature for an hour. The amount of flavonoids was expressed as $\mu \mathrm{g}$ of Quercitin equivalent $(\mathrm{QE}) / \mathrm{mL}$. 


\section{Total antioxidant content (TAC)}

Total antioxidant activity of the samples was determined by Ferric Reducing Antioxidant Potential (FRAP) assay, [34] wherein the stock solutions included $300 \mathrm{mM}$ acetate buffer $\left(3.1 \mathrm{~g} \mathrm{C}_{2} \mathrm{H}_{3} \mathrm{NaO}_{2} \cdot 3 \mathrm{H}_{2} \mathrm{O}\right.$ and $\left.16 \mathrm{~mL} \mathrm{C}_{2} \mathrm{H}_{4} \mathrm{O}_{2}\right), \mathrm{pH}$ 3.6, $10 \mathrm{mM}$ TPTZ (2,4,6-tripyridyl- s-triazine) solution in $40 \mathrm{mM} \mathrm{HCl}$ and $20 \mathrm{mM} \mathrm{FeCl} 3 \cdot 6 \mathrm{H}_{2} \mathrm{O}$ solution. The fresh working solution was prepared by mixing $25 \mathrm{~mL}$ acetate buffer, $2.5 \mathrm{~mL}$ TPTZ and $2.5 \mathrm{~mL} \mathrm{FeCl}{ }_{3} \cdot 6 \mathrm{H}_{2} \mathrm{O}$. The temperature of the reaction mixture was raised to $37^{\circ} \mathrm{C}$. $0.2 \mathrm{~mL}$. The sample was allowed to react with $3 \mathrm{~mL}$ of the FRAP solution for $30 \mathrm{~min}$ in the dark condition [35] forming a colored complex. Absorbance of the colored solution (ferrous tripyridyltriazine complex) was taken at $593 \mathrm{~nm}$ using UV-vis spectrophotometer (Labomed, USA). The total antioxidant activity was determined in terms of $\mu \mathrm{M}$ of $\mathrm{Fe}(\mathrm{II})$ of equivalent $(\mathrm{FE}) / \mathrm{mL}$ using precalibrated data on standards.

\section{Determination of antibacterial activity of biosynthesized silver nanoparticles and its minimum inhibitory concentration (MIC)}

The antibacterial activity of biosynthesized AgNps was evaluated using well diffusion technique. Sterile Mueller Hilton agar plates were prepared and swabbed with $24 \mathrm{~h}$ inoculum culture of waterborne pathogenic microorganism $E$. coli or $S$. aureus. To analyze the antibacterial property of the biosynthesized AgNps, two wells were punched onto the individual inoculated plates. $50 \mu \mathrm{L}$ of the extract was used as a control against the same volume of the silver nanoparticle suspension in each of the wells. The plates were incubated for $24 \mathrm{~h}$ at $35^{\circ} \mathrm{C}$ to observe the formation of zone of inhibition.

In order to determine the antibacterial activity of biosynthesized AgNps in terms of their minimum inhibitory concentration upon $E$. coli or $S$. aureus strains, macrodilution method [36] was used. Culture strains of E. coli and S. aureus (Mc Farland 0.5 standard) were prepared. The stock suspension of biosynthesized $\mathrm{Ag}$ nanoparticles of $102.4 \mu \mathrm{g} / \mathrm{mL}$ concentration in Mueller Hilton broth was suitably diluted to prepare the suspensions with concentrations ranging from 51.2, 25.6, 12.8, 6.4, 3.2, $1.5,0.8,0.4$ to $0.2 \mu \mathrm{g} / \mathrm{mL}$ for each of the bacterial strains. The standardized culture solutions were added to these suspensions of $\mathrm{AgNps}$ and incubated at $30{ }^{\circ} \mathrm{C}$. The concentration of $\mathrm{AgNps}$ at which no visual growth was observed was indicative of the minimum inhibitory concentration of the AgNps. Thus, the concentration of $\mathrm{Ag}$ nanoparticles at which the bacterial growth was completely inhibited was noted as the minimum inhibitory concentration.

\section{Results and discussion}

Many routes of synthesis of nanoparticles have been attempted, but green synthesis or biosynthesis of nanoparticles from plant material extract has been gaining popularity in the recent times for the benign conditions offered by this process and its simplicity in application. The current method adopted for aqueous biosynthesis of AgNps mediated by teak leaf extract under ambient condition demonstrates a change in color of the reaction mixture comprising of the precursor salt and extract from pale red to deep brown initially. This change in color is attributed to the formation of $\mathrm{AgNps}[37,38]$ and occurs through the surface Plasmon vibration of the AgNps [39], indicating the reduction of the silver precursor salt $\left(\mathrm{AgNO}_{3}\right)$ by the bioactive components present in the teak leaf extract into metallic AgNps.

\section{Characterization of the biosynthesized silver nanoparticles}

To confirm the formation of nanoparticles, the synthesized nanoparticles were characterized using UV-vis spectroscopic analysis; the UV-vis spectra as presented in Fig. 1 revealed the surface Plasmon peak characteristic for metallic AgNps located at around $420 \mathrm{~nm}$ [27, 40, 41] and the SPR peak intensities were found to increase with time indicating the reduction of $\mathrm{Ag}$ ions to silver and the formation of AgNps. The intensity of the SPR peak increased as the reaction time increased, which indicated the increased concentrations of the AgNps [42]. The peak became narrower as the time increased. Narrow peaks reveal that the particles in suspension are monodispersed [42]. From Fig. 1, it is observed that as the reaction proceeded the synthesized nanoparticles turn more monodispersed. The narrow peak at $24 \mathrm{~h}$ indicates that the nanoparticles do not agglomerate with passage of time, thus confirming the stability as well as the monodispersity of the AgNps being biosynthesized.

$\mathrm{X}$-ray diffractogram of biosynthesized AgNps is shown in Fig. 2. XRD analysis revealed the Face Centered Cubic structure of metallic crystalline $\mathrm{AgNp}$; peaks belonging to (111), (200), (220), (311) and (211) planes of crystalline structure were observed in the diffractogram at $2 \theta$ values of $38.41,44.75,64.79,77.31$ and 81.85 , respectively. The presence of these peaks agrees with the Braggs reflection of AgNps and indicates nanocrystalline structure of the silver particles biosynthesized by teak leaf extract. Broader peaks signify the formation of smaller nanoparticles. The size of the nanoparticles was calculated using Full width at half maximum data through Scherrer's formula presented as Eq. (2): 
Fig. 1 UV-vis spectrum of silver nanoparticles during biosynthesis over a period of $24 \mathrm{~h}$

Fig. $2 \mathrm{X}$ - ray diffractogram of the biosynthesized silver nanoparticles by teak leaf extract
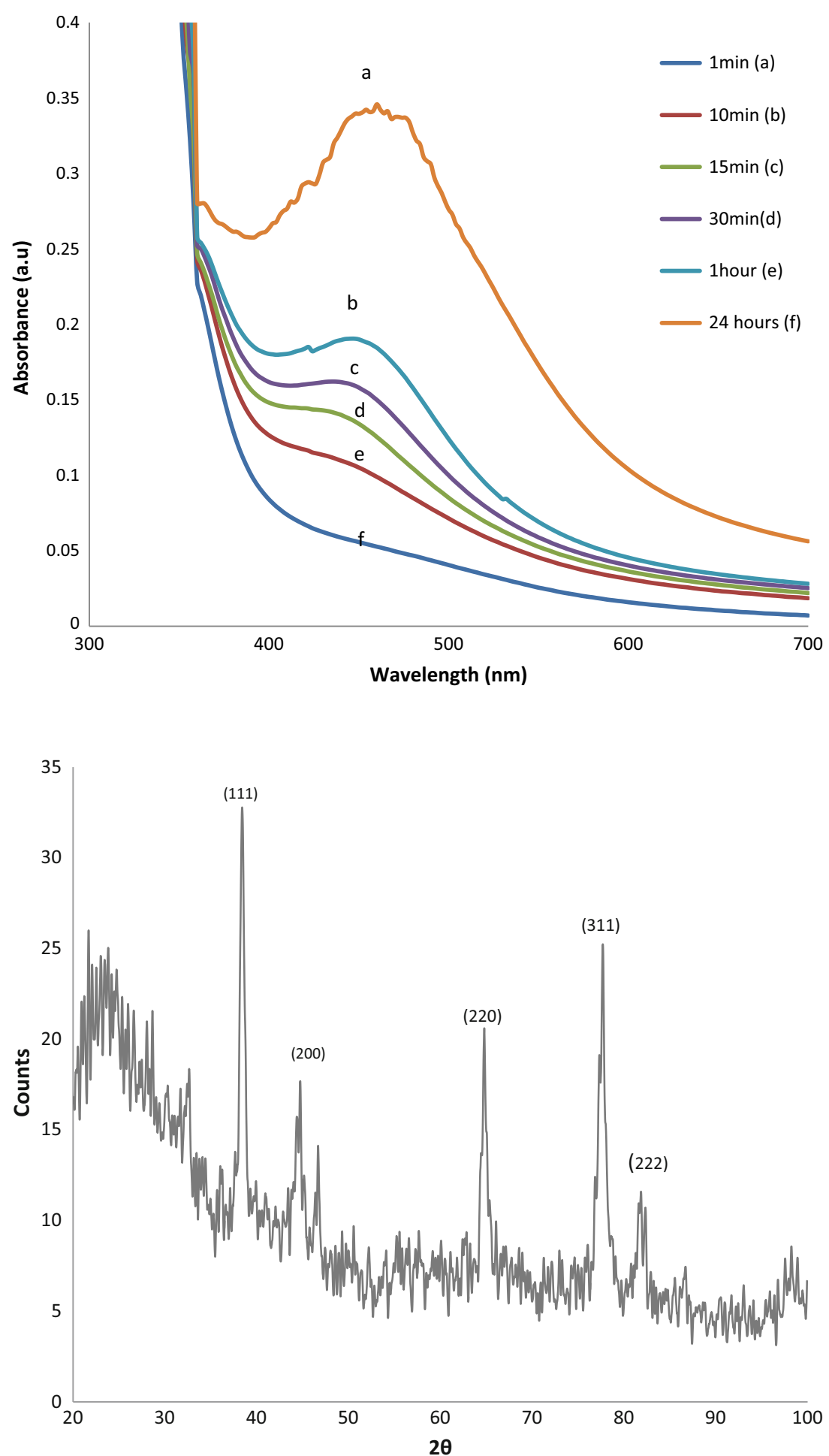

$D=\frac{K \lambda}{\beta_{\frac{1}{2}} \cos \theta}$

Equation (2) uses the reference peak width at angle $\theta$, where $\lambda$ is the X-ray wavelength $(1.5418 \AA), \beta_{1 / 2}$ is the width of the XRD peak at half height and $K$ is a shape factor (0.9). The average size of the AgNps was approximately calculated to be around $28.02 \mathrm{~nm}$.

FTIR analysis was conducted on the biosynthesized AgNps and the IR spectra shown in Fig. 3 revealed a sharp peak at $2358 \mathrm{~cm}^{-1}$ which can be attributed to the $\mathrm{N}-\mathrm{H}$ stretching vibrations, $1218.8 \mathrm{~cm}^{-1}$ to $\mathrm{C}-\mathrm{O}$ stretching of 
Fig. 3 FTIR spectra of biosynthesized silver nanoparticles

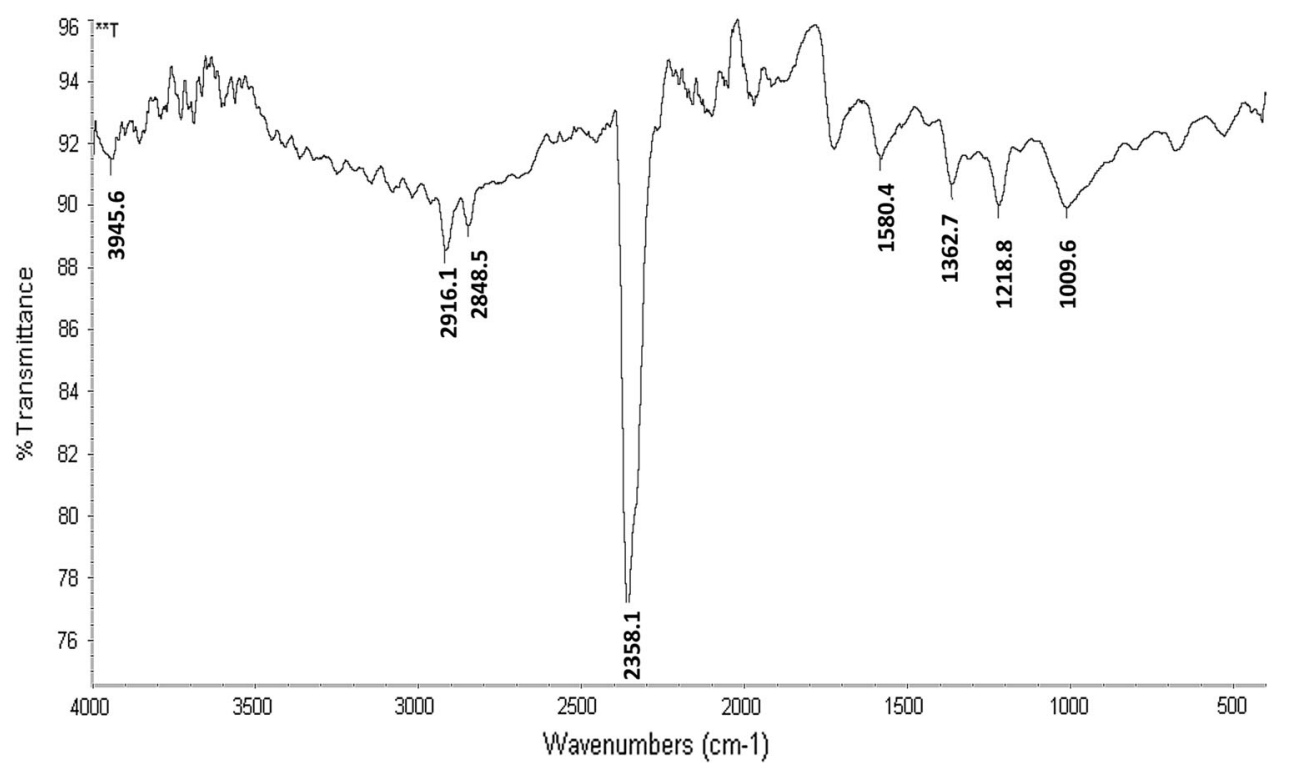

polyols like hydroxyflavones, $1010 \mathrm{~cm}^{-1}$ to $\mathrm{C}-\mathrm{N}$ stretching vibrations of aliphatic amines or to alcohols and phenols indicating that phenols also play an important role in the reduction of the precursor salt. The peak at $1362.7 \mathrm{~cm}^{-1}$ indicates the presence of residual $\mathrm{NO}_{3}^{-}$along with the biosynthesized nanoparticles: $1580.4 \mathrm{~cm}^{-1}$ can be attributed to $\mathrm{C}-\mathrm{O}$ stretching vibrations, while 2916.1 and $2848.5 \mathrm{~cm}^{-1}$ correspond to amide linkages. The fingerprint thus obtained suggests that bound and unbound amide linkages belonging to aromatic rings, ethers and polyphenols are the bioactive components that act as reducing and stabilizing agents towards the biosynthesized AgNps [43]. Researchers have attributed the bioactive components such as antioxidants, flavonoids, terpenes, acids, sugars and proteins to reduce the precursor salt as well as cap the biosynthesized AgNps [28].

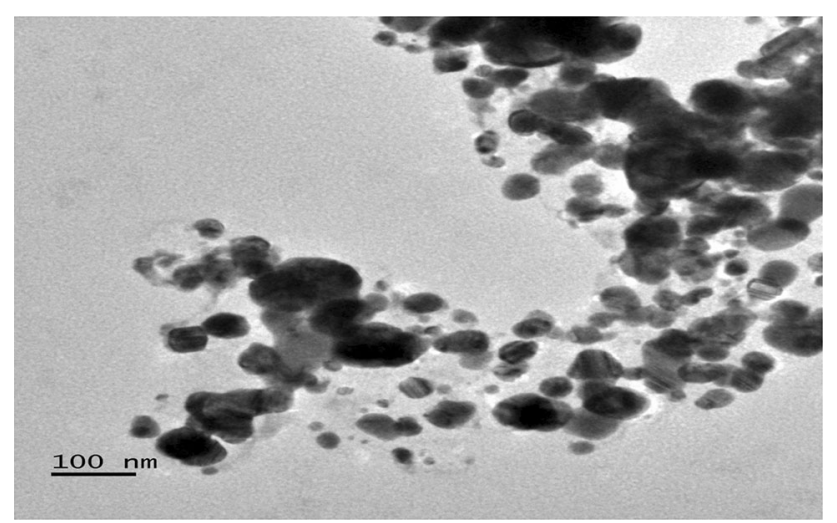

Fig. 4 Transmission electron microscopic image revealing the spherical nature of biosynthesized nanoparticles
Transmission electron microscopic image shown in Fig. 4 reveals the spherical nature of the biosynthesized AgNps. The average particle size was determined using Image J software (Total count 36particles) and was determined to be $26.36 \mathrm{~nm}$ which is in agreement with the XRD results. The Energy dispersive $\mathrm{X}$ - ray analysis (EDX) shown in Fig. 5, confirms the presence of the metallic AgNps along with the peaks for carbon and oxygen, indicating the presence of plant-based capping agents present on the surface of the biosynthesized AgNps.

\section{Role of bioactive compounds present in the extract in mediating the biosynthesis of AgNps and the yield of nanoparticles}

Teak leaves are known to contain a huge repertoire of bioactive compounds as stated earlier. Several reports

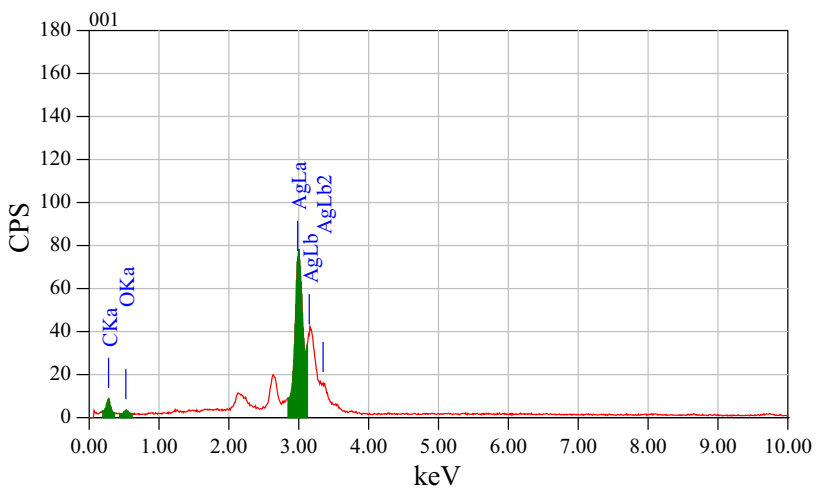

Fig. 5 EDX analysis showing elemental composition of silver nanoparticles 
pertaining to these compounds as reducing and capping agents are available. Compounds such as flavanoids, terpenoids and soluble proteins have been reported to act as capping agents [44]. Dwivedi and Gopal [40], have stated that the presence of phenolic antioxidant group leads to the oxidation-reduction reactions which in turn lead to the conversion of silver nitrate to AgNps. The leaf extract was initially analyzed for the total phenol, total flavonoid and total antioxidant content to determine the presence of these compounds. The same analysis was also conducted on the supernatant of the synthesis mixture after the biosynthesis to determine if these bioactive compounds act as reducing and capping agents. Figure $6 \mathrm{a}-\mathrm{c}$ presents the total phenolic content, total flavonoid content and total antioxidant activity, respectively, in the extract and in the supernatant after biosynthesis. These figures depict the subsequent diminution of the bioactive compounds after biosynthesis AgNps, consequently proving these bioactive compounds act as reducing and capping agents. These results are also found to be in agreement with the result obtained through FTIR analysis of the AgNps. It has been stated that the phenolic compounds are responsible for the subsequent reduction of the precursor salt $\mathrm{AgNO}_{3}$ to $\mathrm{AgNps}$ [45].
Percentage yield of AgNps was determined as described in Sect. 2.8 using Eq. (1) and was found to be $97 \%$. Thus the whole process can be considered to be an eco-friendly, beneficial and convenient way of utilizing the refused teak leaves obtained through lumbering and diversion of the potency of the bioactive compounds towards biosynthesizing AgNps.

\section{Antibacterial activity of biosynthesized silver nanoparticles}

Silver has been famed for its antimicrobial property since time immemorial, thus finding its way into food packaging and pharmaceutical industries. Silver at its nanoscale structure has been proven to be better than its bulkier counterparts. AgNps are potentially more penetrative into the biofilms than antimicrobial agents and have longer shelf life being an element [4] proving to be quite toxic to bacteria [46] and fungi [47]. A clear zone of inhibition of $\sim 16$ and $\sim 18 \mathrm{~mm}$ is observed after incubation in the plates around the wells containing biosynthesized silver nanoparticles as seen in Fig. 7a, b indicating the antibactericidal effect of the silver nanoparticle over E. coli (Gram
Fig. 6 Concentration of bioactive components before biosynthesis (in extract) and after biosynthesis (in synthesis mixture) of Ag nanoparticles. a Total phenolic content, $\mathrm{b}$ total flavonoid content, c total antioxidant content. (Error bars are with respect to standard deviation)
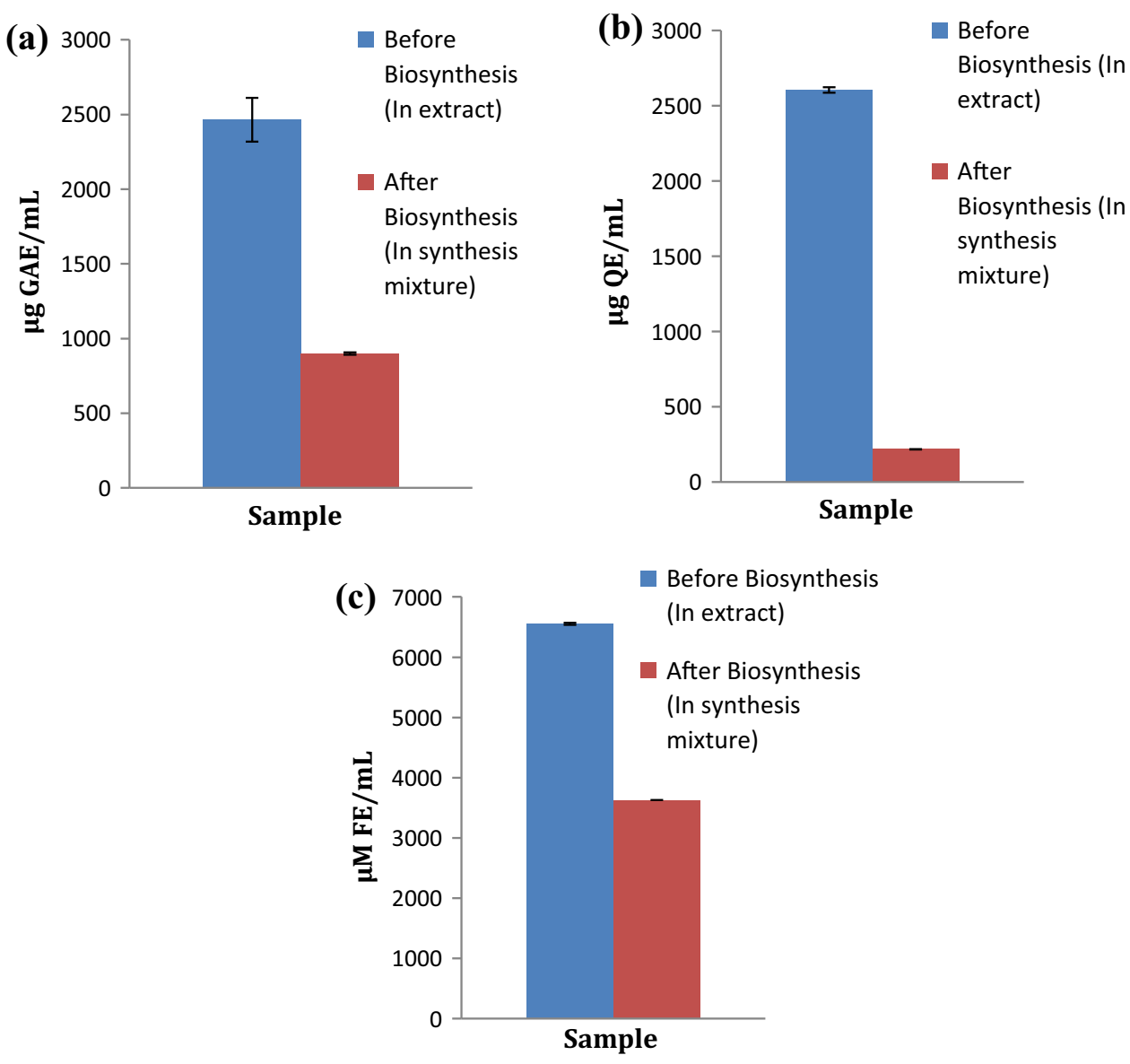
Fig. 7 Well diffusion assay of antibacterial property of biosynthesized silver nanoparticle against a $E$. coli with extract as control. b Against $S$. aureus with extract as control
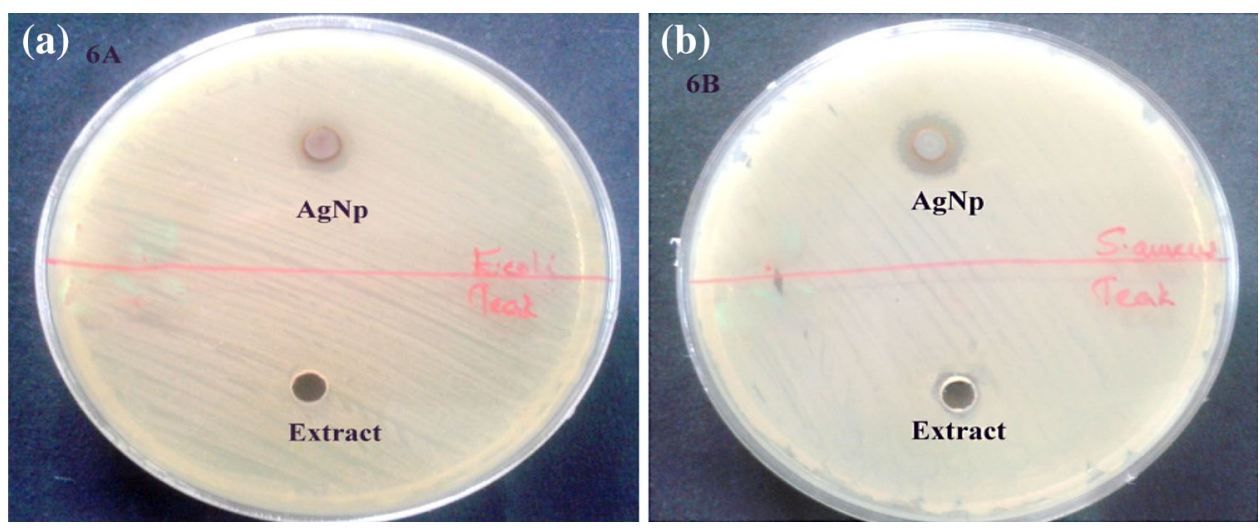

negative strain) and $S$. aureus (Gram Positive strain), respectively. Zones of inhibition with only extract are very less as compared to those with biosynthesized $\mathrm{Ag}$ nanoparticles as shown in Fig. 7a, b. In order to determine concentration-dependent antibacterial activity of the biosynthesized AgNps, the minimum inhibitory concentration (MIC) of these nanoparticles upon E. coli and $S$. aureus was determined by employing broth macro dilution method. MIC of AgNps was determined by the visual observance of a clear solution in the culture tubes containing $\mathrm{AgNp}$ suspension of various concentrations after $24 \mathrm{~h}$ of incubation with the cell culture, indicating the inhibition of bacterial growth by AgNps. For both E. coli and $S$. aureus strains, the MIC was determined to be
$25.6 \mu \mathrm{g} / \mathrm{mL}$ of AgNps as depicted in Fig. 8a, b, respectively. Kim and co-workers [48] reported $100 \mu \mathrm{g} / \mathrm{mL}$ of $\mathrm{AgNps}$ as the MIC against $S$. aureus and $E$. coli used in their studies while the MIC value of AgNps synthesized using aqueous teak leaves is $25.6 \mu \mathrm{g} / \mathrm{mL}$. This indicates that biosynthesized AgNps exhibit better antibactericidal activity in comparison to chemically synthesized AgNps. The enhanced antibacterial activity may be owing to the small size of the biosynthesized nanoparticles and/or due to the presence of capping of bioactive compounds. The AgNps biosynthesized using the aqueous extract of teak leaves, an agrowaste from timber industry, exhibit effective antibactericidal properties and have been found to exhibit similar or better antibacterial property as compared to
Fig. 8 Minimum inhibitory concentration (MIC) by broth macrodilution of teak leaf mediated Agnps against a E. coli b against $S$. aureus

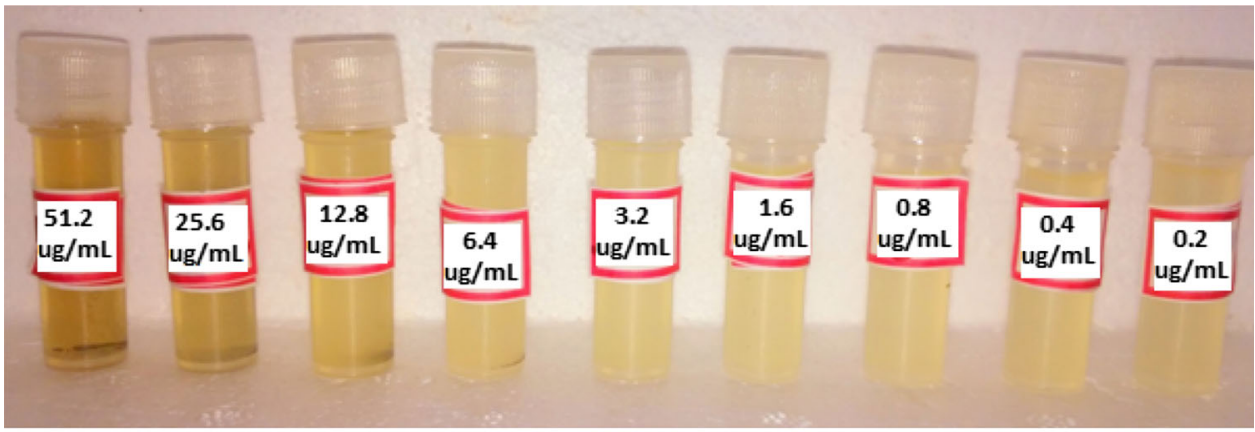

(a)

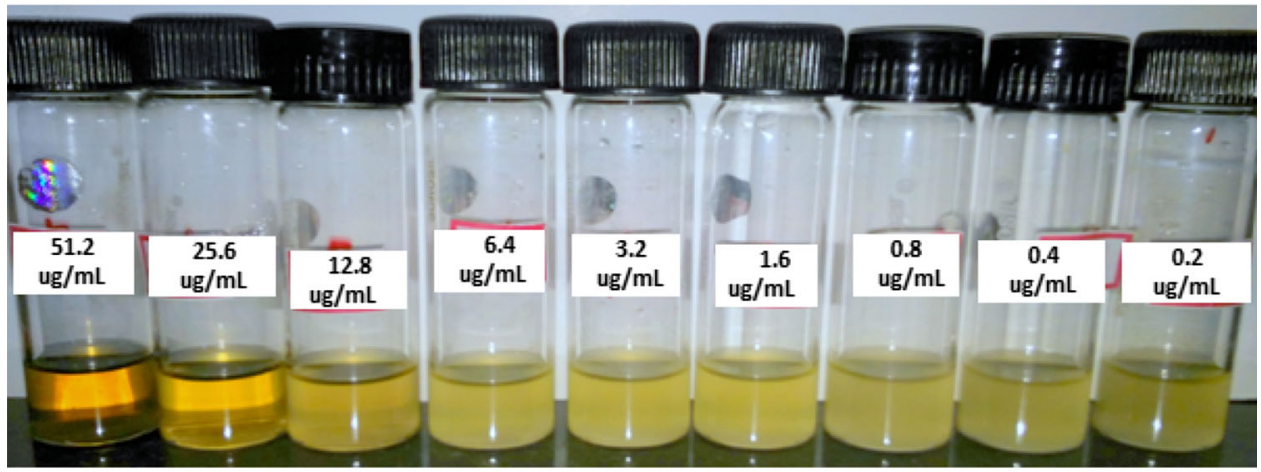

(b) 
AgNps synthesized from other sources or methods. Teak leaves that occur as agrowaste were used in the presently reported biosynthesis process. The process occurs at ambient conditions with limited usage of energy, without the involment of toxic organic solvents, making the biosynthesis process potentilally energy efficient, ecofriendly and economical. The biosynthesized AgNps have potential application in water purifiers, antibacterial fabrics, sportswear and in cosmetics as antibacterial agent and the process used for its synthesis being greener is highly beneficial from environmental, energy consumption and economic perspectives.

\section{Conclusion}

The multitude of bioactive compounds present in the unharnessed agrowaste resource of teak leaves were successfully channeled to synthesize AgNps with a high yield of $97 \%$. The bioactive compounds were attributed to the reduction of the precursor salt into $\mathrm{AgNps}$ and subsequent capping of the AgNps synthesized. Teak leaf aqueous extract mediated AgNps were characterized using UV-vis spectrometry, XRD, TEM and EDX and the results confirmed the formation of spherical shaped AgNps with an approximate average size of $26-28 \mathrm{~nm}$. The bioactive compounds such as phenolics, flavonoids and antioxidants present in teak leaves extract were found to be utilized during biosynthesis process as reducing and capping agents. FTIR analysis further confirmed the role of bioactive compounds as reducing and stabilizing agents in biosynthesis process. The synthesis was carried out under ambient conditions and the AgNps thus synthesized demonstrated remarkable antibacterial activity with MIC of $25.6 \mu \mathrm{g} / \mathrm{mL}$ against the pathogenic bacteria such as $S$. aureus and E. coli, making it ideal for medical and therapeutic applications. Exploitation of food and commercial value plant products for nanoparticle synthesis diminishes the overall efficacy of the synthesis process, while utilization of plentiful agrowaste resources leads towards ecofriendly and self- sustained method of nanoparticle synthesis. The biosynthesized AgNps have potential application in water purifiers, antibacterial fabrics, sportswear and in cosmetics as antibacterial agent and the process used for its synthesis being greener is highly beneficial from environmental, energy consumption and economic perspectives.

Open Access This article is distributed under the terms of the Creative Commons Attribution 4.0 International License (http://crea tivecommons.org/licenses/by/4.0/), which permits unrestricted use, distribution, and reproduction in any medium, provided you give appropriate credit to the original author(s) and the source, provide a link to the Creative Commons license, and indicate if changes were made.

\section{References}

1. Rai, M., Yadav, A., Gade, A.: Silver nanoparticles as a new generation of antimicrobials. Biotechnol. Adv. 27, 76-83 (2009)

2. Salata, O.V.: Applications of nanoparticles in biology and medicine. J. Nanobiotechnol. 2, 3 (2004)

3. Hu, A., Guo, J.Y., Alarifi, H., Patane, G., Zhou, Y., Compagnini, G., Xu, C.X.: Low temperature sintering of Ag nanoparticles for flexible electronics packaging. Appl. Phys. Lett. 97, 153117 (2010)

4. Durán, N., Marcato, P.D., De Souza, G.I., Alves, O.L., Esposito, E.: Antibacterial effect of silver nanoparticles produced by fungal process on textile fabrics and their effluent treatment. J. Biomed. Nanotechnol. 3, 203-208 (2007)

5. Kokura, S., Handa, O., Takagi, T., Ishikawa, T., Naito, Y., Yoshikawa, T.: Silver nanoparticles as a safe preservative for use in cosmetics. Nanomed. Nanotechnol. Biol. Med. 6, 570-574 (2010)

6. Chau, J.L.H., Hsu, M.K., Hsieh, C.C., Kao, C.C.: Microwave plasma synthesis of silver nanopowders. Mater. Lett. 59, 905-908 (2005)

7. Lin, Y., Watson, K.A., Fallbach, M.J., Ghose, S., Smith, J.G., Donavon, M.D., Wei, C., Crooks, R.E., Connell, J.W.: Rapid, solventless, bulk preparation of metal nanoparticle-decorated carbon nanotubes. Acs Nano. 3, 871-884 (2009)

8. Pal, A., Shah, S., Devi, S.: Microwave-assisted synthesis of silver nanoparticles using ethanol as a reducing agent. Mater. Chem. Phys. 114, 530-532 (2009)

9. Pillai, Z.S., Kamat, P.V.: What factors control the size and shape of silver nanoparticles in the citrate ion reduction method? J. Phys. Chem. B. 108, 945-951 (2004)

10. Panáček, A., Kvitek, L., Prucek, R., Kolar, M., Vecerova, R., Pizurova, N., Zboril, R.: Silver colloid nanoparticles: synthesis, characterization, and their antibacterial activity. J. Phys. Chem. B. 110, 16248-16253 (2006)

11. Sun, Y., Xia, Y.: Shape-controlled synthesis of gold and silver nanoparticles. Science 298, 2176-2179 (2002)

12. Vigneshwaran, N., Ashtaputre, N.M., Varadarajan, P.V., Nachane, R.P., Paralikar, K.M., Balasubramanya, R.H.: Biological synthesis of silver nanoparticles using the fungus Aspergillus flavus. Mater. Lett. 61, 1413-1418 (2007)

13. Shahverdi, A.R., Minaeian, S., Shahverdi, H.R., Jamalifar, H., Nohi, A.A.: Rapid synthesis of silver nanoparticles using culture supernatants of Enterobacteria: a novel biological approach. Process Biochem. 42, 919-923 (2007)

14. Govindaraju, K., Kiruthiga, V., Kumar, V.G., Singaravelu, G.: Extracellular synthesis of silver nanoparticles by a marine alga, Sargassum wightii Grevilli and their antibacterial effects. J. Nanosci. Nanotechnol. 9, 5497-5501 (2009)

15. Christensen, L., Vivekanandhan, S., Misra, M., Mohanty, A.K.: Biosynthesis of silver nanoparticles using Murraya koenigii (curry leaf): an investigation on the effect of broth concentration in reduction mechanism and particle size. Adv. Mat. Lett. 2, 429-434 (2011)

16. Zargar, M., Hamid, A.A., Bakar, F.A., Shamsudin, M.N., Shameli, K., Jahanshiri, F., Farahani, F.: Green synthesis and antibacterial effect of silver nanoparticles using Vitex Negundo L. Molecules 16, 6667-6676 (2011)

17. Shameli, K., Ahmad, M.B., Zamanian, A., Sangpour, P., Shabanzadeh, P., Abdollahi, Y., Zargar, M.: Green biosynthesis of silver nanoparticles using Curcuma longa tuber powder. Int. J. Nanomed. 7, 5603-5610 (2012)

18. Roopan, S.M., Rohita, R., Madhumitha, G., Rahuman, A.A., Kamaraj, C., Bharathi, A., Surendra, T.V.: Low-cost and ecofriendly phyto-synthesis of silver nanoparticles using Cocos 
nucifera coir extract and its larvicidal activity. Ind. Crops. Prod. 43, 631-635 (2013)

19. Vijayakumar, M., Priya, K., Nancy, F.T., Noorlidah, A., Ahmed, B.A.: Biosynthesis, characterisation and anti-bacterial effect of plant-mediated silver nanoparticles using Artemisia nilagirica. Ind. Crops Prod. 41, 235-240 (2013)

20. Sathishkumar, M., Sneha, K., Won, S.W., Cho, C.W., Kim, S., Yun, Y.S.: Cinnamon zeylanicum bark extract and powder mediated green synthesis of nano-crystalline silver particles and its bactericidal activity. Colloids Surf. B Biointerfaces. 73, 332-338 (2009)

21. Ankamwar, B., Damle, C., Ahmad, A., Sastry, M.: Biosynthesis of gold and silver nanoparticles using Emblica officinalis fruit extract, their phase transfer and transmetallation in an organic solution. J. Nanosci. Nanotechnol. 5, 1665-1671 (2005)

22. Mukunthan, K.S., Elumalai, E.K., Patel, T.N., Murty, V.R.: Catharanthus roseus: a natural source for the synthesis of silver nanoparticles. Asian Pac. J. Trop. Biomed. 1, 270-274 (2011)

23. Kore, K. J., Pradip, Jadhav, J., Shete, R. V., Shetty, S. C.: Diuretic property of Tectona grandis leaves aqueous extract in Wistar rats. Inter. J. Pharm. Res. Dev. 3, 141-146 (2011)

24. Rao, K.N.V., Aradhana, R., Banjii, D., Chaitanya, R.S.N., Anil Kumar, A.V.: In-vitro anti-oxidant and free radical scavenging activity of various extracts of Tectona grandis. Linn Leaves. J. Pharm. Res. 4, 440-442 (2011)

25. Purushotham, G., Arun, P., Jayarani, J.J., Vasnthakumari, R., Sankar, L., Raviprakash, B.R.: Synergistic in vitro antibacterial activity of Tectona grandis leaves with tetracycline. Int. J. Pharm. Tech. Res. 2, 519-523 (2010)

26. David, E., Elumalai, E.K., Prasad, T.N.V.K.V., Venkata, K., Nagajyothi, P.C.: Green synthesis of silver nanoparticle using Euphorbia hirta $\mathrm{L}$ and their antifungal activities. Arch. Appl. Sci. Res. 2, 76-81 (2010)

27. Cruz, D., Falé, P.L., Mourato, A., Vaz, P.D., Serralheiro, L.M., Lino, A.R.: Preparation and physicochemical characterization of Ag nanoparticles biosynthesized by Lippia citriodora (Lemon Verbena). Colloids Surf. B Biointerfaces 81, 67-73 (2010)

28. Krishnaraj, C., Jagan, E.G., Rajasekar, S., Selvakumar, P., Kalaichelvan, P.T., Mohan, N.: Synthesis of silver nanoparticles using Acalypha indica leaf extracts and its antibacterial activity against water borne pathogens. Colloids Surf. B Biointerfaces 76, 50-56 (2010)

29. Singhal, G., Bhavesh, R., Kasariya, K., Sharma, A.R., Singh, R.P.: Biosynthesis of silver nanoparticles using Ocimum sanctum (Tulsi) leaf extract and screening its antimicrobial activity. J. Nanopart. Res. 13, 2981-2988 (2011)

30. Foldbjerg, R., Dang, D.A., Autrup, H.: Cytotoxicity and genotoxicity of silver nanoparticles in the human lung cancer cell line, A549. Arch. Toxicol. 85, 743-750 (2011)

31. Chew, L., Yik, C., Wan, L., Elaine, T., Ling P., Lim, Y., Yau, G., Kheng, J., Stanlas, J.: Assessment of phytochemical content, polyphenolic composition, antioxidant and antibacterial activities of Leguminosae medicinal plants in Peninsular Malaysia. BMC Complement. Altern. Med. 12, 1-1. http://www.biomedcentral. com/1472-6882/11/12 (2010)

32. Wolfe, K., Wu, X., Liu, R.H.: Antioxidant activity of apple peels. J. Agr. Food Chem. 51, 609-614 (2010)

33. Ordon-Ez, A.A.L., Gomez, J.D., Vattuone, M.A., Isla, M.I.: Antioxidant activities of Sechium edule (Jacq.) Swart extracts. Food Chem. 97, 452-458 (2006)
34. Adedapo, A.A., Jimoh, F.O., Koduru, S., Masika, P.J., Afolayan, A.J.: Evaluation of the medicinal potentials of the methanol extracts of the leaves and stems of Halleria lucida. Bioresour. Technol. 99, 4158-4163 (2008)

35. Benzie, I.F.F., Strain, J.J.: The ferric reducing ability of plasma (FRAP) as a measure of "antioxidant power': the FRAP assay. Ana. Biochem. 239, 70-76 (1996)

36. Antibiotic susceptibility testing of aquaculture associated bacteria with the broth macrodilution method (Mic determination) SOP ASIARESIST, Laboratory of Microbiology, K. L. Ledeganckstr. 35, B-9000 Gent (Belgium)

37. Basavaraja, S., Balaji, S.D., Lagashetty, A., Rajasab, A.H., Venkataraman, A.: Extracellular biosynthesis of silver nanoparticles using the fungus Fusarium semitectum. Mater. Res. Bull. 43, 1164-1170 (2008)

38. Rastogi, L., Arunachalam, J.: Sunlight based irradiation strategy for rapid green synthesis of highly stable silver nanoparticles using aqueous garlic (Allium sativum) extract and their antibacterial potential. Mater. Chem. Phys. 129, 558-563 (2011)

39. Wei, X., Luo, M., Li, W., Yang, L., Liang, X., Xu, L., Kong, P., Liu, H.: S ynthesis of silver nanoparticles by solar irradiation of cell-free Bacillus amyloliquefaciens extracts and AgNO3. Bioresour. Technol. 103, 273-278 (2012)

40. Dwivedi, A.D., Gopal, K.: Biosynthesis of silver and gold nanoparticles using Chenopodium album leaf extract. Colloids Surf. A. Physicochem. Eng. Aspects. 369, 27-33 (2010)

41. Sathishkumar, M., Sneha, K., Yun, Y.S.: Immobilization of silver nanoparticles synthesized using Curcuma longa tuber powder and extract on cotton cloth for bactericidal activity. Bioresour. Technol. 101, 7958-7965 (2010)

42. Khalil, M.M., Ismail, E.H., El-Baghdady, K.Z., Mohamed, D.: Green synthesis of silver nanoparticles using olive leaf extract and its antibacterial activity. Arabian J. Chem. 7, 1131-1139 (2014)

43. Prathna, T.C., Chandrasekaran, N., Raichur, A.M., Mukherjee, A.: Biomimetic synthesis of silver nanoparticles by Citrus limon (lemon) aqueous extract and theoretical prediction of particle size. Colloids Surf. B Biointerfaces. 82, 152-159 (2011)

44. Ramamurthy, C. H., Padma, M., Samadanam Daisy Mariya I., Mareeswaran, R., Suyavaran, A., Suresh Kumar, M., Premkumar, B.: The extra cellular synthesis of gold and silver nanoparticles and their free radical scavenging and antibacterial properties. Colloids Surf. B: Biointerfaces. 102, 808-815 (2013)

45. Sethuraman, M.G., Edison, T.J.I.: Instant green synthesis of silver nanoparticles using Terminalia chebula fruit extract and evaluation of their catalytic activity on reduction of methylene blue. Proc. Biochem. 47, 1351-1357 (2012)

46. MubarakAli, D., Thajuddin, N., Jeganathan, K., Gunasekaran, M.: Plant extract mediated synthesis of silver and gold nanoparticles and its antibacterial activity against clinically isolated pathogens. Colloids Surf. B: Biointerfaces. 85, 360-365 (2011)

47. Nazeruddin, G.M., Prasad, N.R., Waghmare, S.R., Garadkar, K.M., Mulla, I.S.: Extracellular biosynthesis of silver nanoparticle using Azadirachta indica leaf extract and its anti-microbial activity. J. Alloys Compd. 583, 272-277 (2014)

48. Kim, S.H., Lee, H.S., Ryu, D.S., Choi, S.J., Lee, D.S.: Antibacterial activity of silver-nanoparticles against Staphylococcus aureus and Escherichia coli. Korean J. Microbiol. Biotech. 9, 77-85 (2011) 